\title{
Strength Behaviour of Blended Self Cured Concrete made with Cement by partial replacement of Supplementary Cementitious Materials (SCM's)
}

\author{
C Vivek $\mathrm{Kumar}^{1}$, MD Aiman Parvez ${ }^{2}$ and $T$ Srinivas $^{31}$ \\ ${ }^{1}$ Assistant Professor, Civil Engineering Department, GRIET, Hyderabad, Telangana, India. \\ ${ }^{2}$ PG Student, Civil Engineering Department, GRIET, Hyderabad, Telangana, India. \\ ${ }^{3}$ Professor, Civil Engineering Department, GRIET, Hyderabad, Telangana, India.
}

\begin{abstract}
At Present Water is the most essential material in the modern era. In general, Curing of concrete is retaining moisture in the concrete for the period of early ages precisely within 28 days of placing concrete, to improve anticipated properties. Appropriate curing of concrete is crucial to obtain extreme durability, especially if the concrete is exposed to serve conditions where the surface will be imperiled to excessive wear, assertive solutions, and severe environmental circumstances. Poor curing practices adversely affect the desirable properties of concrete which constitutes a major influence on the permeability of a given concrete.Unpredicted shrinkage and temperature cracks be able to diminish the strength, durability and serviceability properties of the concrete. The surface zone will be critically damaged by increased permeability expected to poor curing. The improvement of shrinkage in concrete is proportionate to the rate of moisture loss in concrete. When concrete is correctly cured, water preserved in concrete would facilitate continuous hydration and enhancement of enough compressive and tensile strength to withstand contraction stresses. The incessant development of strength reduces shrinkage and initial cracks or micro-cracks. As a part of this study, SCMs like Flyash (FA), Ground Granulated furnace Slag (GGBS), Silica Fume (SF). Concrete may be a mixture of cement, aggregates and water with / without suitable admixtures with self-curing agents and various proportions, which resulted in the early strength to reduce the autogenous shrinkage and increase in durability.
\end{abstract}

${ }^{1}$ Corresponding Author Email: srinu.tummala@gmail.com 


\section{INTRODUCTION}

The effective methods to conserve the Mother Nature's resources and additionally minimize the environmental impact is to utilize Supplementary Cementitious Materials (SCMs) by superseding OPC partly or plenarily in concrete. "Since most of SCMs are pozzolanic in nature and hence they are subsidiary in incrementing later strength of concrete, blending of SCMs with cement has many advantages like preserving in cement, utilization of commercial by-products, enhancement of micro structural properties of concrete and reduces environmental impact through minimized greenhouse gases engenderment". Most of the SCMs are industrial by-products which are considered as waste and pollutants when dumped into land or thrown into dihydrogen monoxide bodies. "Therefore, Blending them in concrete becomes safe disposal method for them. Such SCMs are Flyash (FA), Ground Granulated furnace Slag (GGBS), Silica Fume (SF), concrete may be a mixture of cement, aggregates and water with or without suitable admixtures". to achieve desirable strength and other properties, curing is important.

Cement merging with SCMs with considerably higher specific surface than cement, and specifically irregular particles shapes with voids, results in inferior natural philosophy compared to normal cement. GGBS alsoshow offthe pozzolanic properties since it comprises low $\mathrm{CaO}$ as sustainable and eco-friendly substance which can be used in building industry. The main objective of the current study is to determine the mechanical properties the mechanical properties of compression test, split tensile test and flexural test for the blending of Supplementary Cementitious Materials.

\section{MATERIAL PROPERTIES AND INVESTIGATIONS}

To obtain specific experimental data which helps to understand the mechanical behaviour and optimum dosage of Polyethylene Glycol 400 and significance of utilization of Flyash, Ground Granulated furnace Slag and Silica Fume as partial replacement of river sand as fine aggregate, the experimental programme was taken up.

Cement 53-grade OPC confirming to IS: 122691987 was used in the investigation having a specific gravity of 3.21 , specific surface area of $225 \mathrm{~m}^{2} / \mathrm{g}$ and initial and finalsetting times of cement were 35 minimum and 550 minimum respectively.

Fine aggregate as locally available river sand confirming to Zone-2 according to IS: 383-1970, was usedas fine aggregate. The specific gravity and bulk density of sand were 2.62 and $1.5 \mathrm{~g} / \mathrm{cm}^{3}$ respectively. Coarse aggregate used is crushed granite angular aggregate passing through $20 \mathrm{~mm}$ and retained on
$4.75 \mathrm{~mm}$ sieve. "The coarse aggregate used is conforms to IS 383-1970 and is tested as per IS 2386-1963 for its physical properties, its specific gravity 2.6 , Bulk density (loose state) as $1450 \mathrm{~kg} / \mathrm{m}^{3}$ and(compacted state) as 1528 $\mathrm{kg} / \mathrm{m} 3$. Potable water was used in the investigations for both mixing and curing of SCM specimens".

The Flyash obtained from Mettur Thermal Power Station having specific gravity of 2.17 . and composition consisting of silica content as $63.99 \%$,calcium oxide as $1.71 \%$, magnesium oxide of $1.0 \%, \mathrm{pH}$ as 10 and loss onignition as $2.12 \%$.

"GGBS blended concrete is significantly more resistant to the ingress of chloride ions in concrete apart from reduced permeability. GGBS was procured in JSW Steel Ltd, Karnataka mainly having $\mathrm{SiO} 2$ as $35.20 \%$, $\mathrm{Al} 2 \mathrm{O} 3$ as $19 \%$ and $\mathrm{CaO}$ as $34.90 \% "$.

Polyethylene Glycols (PEGs) of low molecular (400) used in the study. The chemicals were mixed with water thoroughly prior to mixing of water in concrete. "A polycarboxylate-type, new-generation high range water reducing admixture confirming to ASTM C494 was used as super plasticizer for improving the flowor workability of mix with decreased water-cement ratio, These admixtures when they disperse in cement agglomerate significantly and reduce the viscosity of thepaste forming a thin film around the cement particles".

Various dosages of "Flyash, GGBS and Silica fume has $65+25+15,65+20+15,65+25+10$ and $65+20+15$ of various mix proportions are determined, in which the optimum dosage of blended elements will arrived for M30 grade of concrete with super plasticizer and PEG 400 as $1 \%$ of the weight of the cement content". Though the specimens

Samples of M30 grade blended concrete beams made with optimum amount of Flyash, GGBS and Silica fume replacement were casted.

The "mix proportioning was done constructed on the approach of Indian Code for mix design for blending concrete M30 of binary, ternary and quaternary blended concretes made with optimum blends of fly ash (FA), Silica fume (SF) and Ground Granulated furnace Slag (GGBS).Numerous trial mixes are showed on number of blended concrete mixes made with the diverse possible combinations of Fly Ash (FA), Silica Fume(SF) and Ground Granulated furnace Slag (GGBS), were to progress several quaternary blended concrete mixes". 
Table 1. Proportions of M30 Concrete

\begin{tabular}{|r|c|c|}
\hline S.No & Material & Quantity $\left(\mathrm{kg} / \mathrm{m}^{3}\right)$ \\
\hline 1. & Cement & 350 \\
\hline 2. & Fine aggregate & 744.25 \\
\hline 3. & Coarse aggregate & 1314.18 \\
\hline 4. & Polyethylene Glycol & 2.28 \\
\hline 5. & Super Plasticizer & 3.5 \\
\hline 6. & Water & 175 \\
\hline 7. & Water cement ratio & 0.4 \\
\hline \multicolumn{2}{|c|}{ Cement: Fine Aggregate: Coarse Aggregate: $\mathrm{w} / \mathrm{c}$ ratio $=$} \\
\hline
\end{tabular}

As per clause 8.2.4.2 of "IS 456-2000, the maximum cement content isrestricted to 450 kilograms per cubic metre of concrete. Later trail mixes, revisedquantities in $\mathrm{kg}$ per cubic metre for grade (M30) blendedconcrete mix are reached without compromising the requiredstrengthproperty".

The computed amount of OPC is $350 \mathrm{~kg}$ and it was separated to pozzolanic materials like Flyash (FA), Ground Granulated furnace Slag (GGBS),Silica Fume (SF) with various dosages arrived from the literature studies formulated in table 1 .

\begin{tabular}{|c|c|c|c|c|c|c|c|c|}
\hline MIX (\%) & CEMENT & FLYASH & GGBS & $\begin{array}{l}\text { SILICA } \\
\text { FUME } \\
\end{array}$ & C.A & F.A & S.P & WATER \\
\hline M1 (100) & 350 & -- & -- & -- & 1314.18 & 744.255 & 3.5 & 140 \\
\hline M2 $(65+25+15)$ & 227.5 & 87.5 & 35 & -- & 1314.18 & 744.255 & 3.5 & 140 \\
\hline M3 $(65+25+15)$ & 227.5 & -- & 87.5 & 35 & 1314.18 & 744.255 & 3.5 & 140 \\
\hline M4 (65+25+15) & 227.5 & 87.5 & -- & 35 & 1314.18 & 744.255 & 3.5 & 140 \\
\hline M5 (65+20+15) & 227.5 & 70 & 52.5 & -- & 1314.18 & 744.255 & 3.5 & 140 \\
\hline M6 (65+20+15) & 227.5 & -- & 70 & 52.5 & 1314.18 & 744.255 & 3.5 & 140 \\
\hline M7 $(65+20+15)$ & 227.5 & 70 & -- & 52.5 & 1314.18 & 744.255 & 3.5 & 140 \\
\hline M8 $(65+25+10)$ & 227.5 & 87.5 & -- & 35 & 1314.18 & 744.255 & 3.5 & 140 \\
\hline M9 $(65+25+10)$ & 227.5 & 87.5 & 35 & -- & 1314.18 & 744.255 & 3.5 & 140 \\
\hline M10 $(65+25+10)$ & 227.5 & -- & 87.5 & 35 & 1314.18 & 744.255 & 3.5 & 140 \\
\hline M11 (65+20+15) & 227.5 & 70 & -- & 52.5 & 1314.18 & 744.255 & 3.5 & 140 \\
\hline M12 $(65+20+15)$ & 227.5 & 70 & 52.5 & -- & 1314.18 & 744.255 & 3.5 & 140 \\
\hline M13 $(65+20+15)$ & 227.5 & 70 & -- & 52.5 & 1314.18 & 744.255 & 3.5 & 140 \\
\hline
\end{tabular}

\section{RESULTS}

Optimum dosage of Polyethylene Glycol (PEG 400) considering the weight loss, water retention capacity of self-cured concrete mixes made with SCM's calculated (in grams) as 17, 25 and 38 according to the curing time of 7,14 and 28 days respectively. Comparing with normal cured concrete, it is 55, 78 and 92 grams "according to the curing time of 7,14 and 28 days correspondingly, optimum dosage of PEG 400 can be further reduced to $0.5 \%$ for higher grades of self-cured concrete mixes". "As per the result of slump cone values, it is concluded that the workability has been improved in the mix percentages $65 \%+25 \%+15 \%$ and slightly decreases as to the other mixes as shown in fig 1. In the mixes produced with Flyash and silica fume have improved the workability and higher strengths compared with the ratio of blending with GGBS and Flyash”.

Concrete cubes of size $150 \mathrm{~mm}$ and cylinders of size 100 $\mathrm{mm} \times 100 \mathrm{~mm} \times 500 \mathrm{~mm}$ were casted with various proportions of Various dosages of Flyash, GGBS and Silica fume has $65+25+15,65+20+15,65+25+10$ and $65+20+15$ with replacement of cement for testing compressive and split tensile strength of blended selfcured concrete.

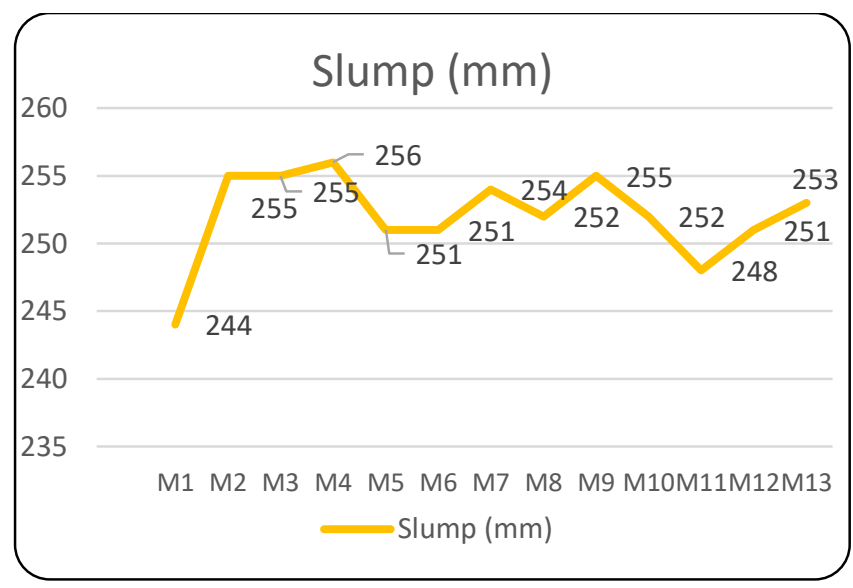

Fig 1.Slump values for M30 blended concrete of several mixes

Table 3. Compressive Strength of various trail mixes

\begin{tabular}{|c|c|c|c|}
\hline \multirow{2}{*}{ MIX (\%) } & \multicolumn{3}{|c|}{ Compressive Strength in MPa (M30) } \\
\cline { 2 - 4 } & 7 days & 14 days & 28 days \\
\hline
\end{tabular}




\begin{tabular}{|c|c|c|c|} 
M1 & 12.48 & 20.15 & 31.21 \\
\hline M2 & 16.04 & 26.67 & 41.12 \\
\hline M3 & 16.79 & 25.6 & 38.16 \\
\hline M4 & 15.52 & 25.89 & 37.85 \\
\hline M5 & 13.06 & 24.52 & 35.21 \\
\hline M6 & 13.97 & 22.52 & 36.76 \\
\hline M7 & 14.03 & 20.78 & 35.07 \\
\hline M8 & 13.36 & 21.42 & 34.25 \\
\hline M9 & 14.08 & 20.76 & 33.53 \\
\hline M10 & 14.64 & 23.78 & 34.86 \\
\hline M11 & 15.97 & 25.29 & 38.95 \\
\hline M12 & 15.17 & 23.9 & 35.29 \\
\hline M13 & 14.25 & 21.19 & 33.93 \\
\hline
\end{tabular}

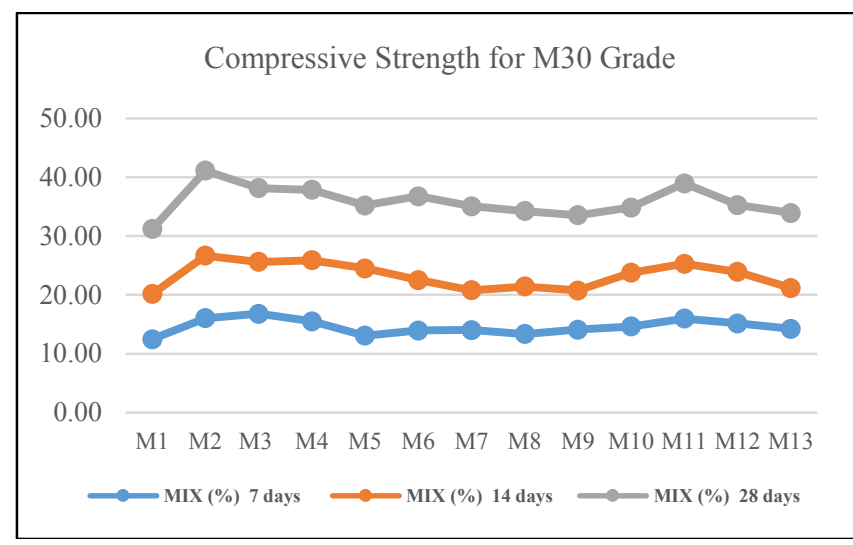

Fig 2. Graph displayingCompressive Strength of various mixes

Table 4. Split Tensile Strength of various trail mixes

\begin{tabular}{|c|c|c|c|}
\hline \multirow{2}{*}{ Mix \% } & \multicolumn{3}{|c|}{ Split Tensile Strength in MPa (M30) } \\
\cline { 2 - 4 } & 7 days & 14 days & 28 days \\
\hline M1 & 1.34 & 2.1 & 3.40 \\
\hline M2 & 1.48 & 3.11 & 4.21 \\
\hline M3 & 1.54 & 3.0 & 4.18 \\
\hline M4 & 1.47 & 2.99 & 4.13 \\
\hline M5 & 1.42 & 2.6 & 4.03 \\
\hline M6 & 1.39 & 2.48 & 4.10 \\
\hline M7 & 1.35 & 2.56 & 4.19 \\
\hline M8 & 1.47 & 2.49 & 3.94 \\
\hline M9 & 1.49 & 2.44 & 3.91 \\
\hline M10 & 1.45 & 2.5 & 3.86 \\
\hline M11 & 1.33 & 2.24 & 3.54 \\
\hline M12 & 1.29 & 2.19 & 3.68 \\
\hline M13 & 1.30 & 2.28 & 3.79 \\
\hline
\end{tabular}

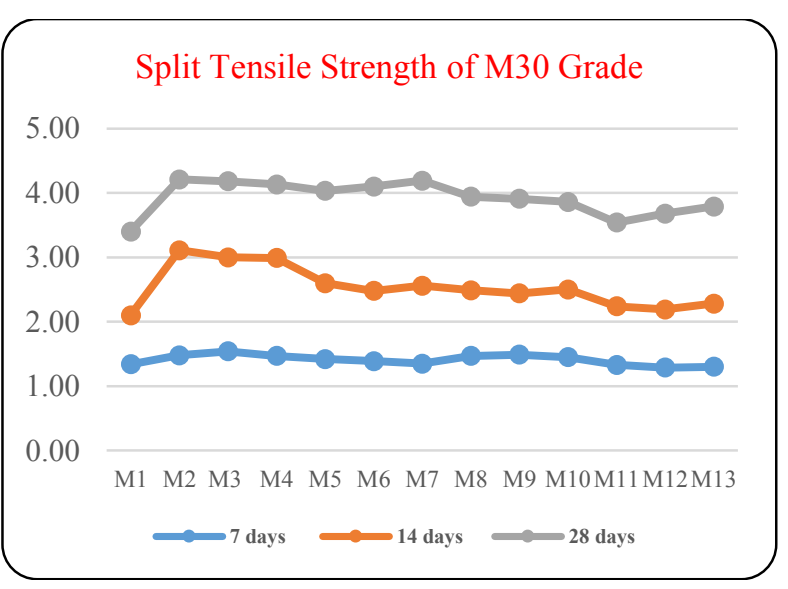

Fig 2. Graph displayingSplit Tensile Strength of various mixes

\section{DISCUSSIONS}

The concrete was cast as per Mix Design M30 grade (IS 10262:2009). The obtained concrete was tested for strength properties. "The different strength tests which includes compression test and split tensile test.The measurements of Polyethylene Glycol 400 were changed from $1 \%$ by weight of the concrete was utilized as selfrelieving operator with that various doses of SNF fluctuated from $1 \%$ by weight of the solid to oneself restoring solid blend and contrasted the test outcome and the triple mixed self-restored concrete, from these final quantities, for various percentage replacement of cement by FA, SF, GGBS and their combinations aretried to optimize the quantities for binary, ternary andquaternary blended SCC mixes of grades considered". The percentage replacements, their correspondingdesired strengths are tabulated in Table-3. In Table-4,final optimal quantities of various grades of SCC mixes along with their total powder content and water /powderratios are mentioned. "In Table-5, compressive strengthsfor various binary, ternary and quaternaryblendedoptimal SCC mixes are tabulated, the performance of self-cured by PEG 400 applied to concrete is the greatest if 45 $\mathrm{kg} / \mathrm{m} 3$ Added water by means of $1 \mathrm{~kg} / \mathrm{m} 3$ PEG 400".

Table 5. Strengths of optimally blended M30 grade concrete

\begin{tabular}{|c|c|c|c|c|}
\hline \multirow{2}{*}{$\begin{array}{l}\text { Mix } \\
\text { No }\end{array}$} & \multirow{2}{*}{$\begin{array}{l}\text { Mix Designation } \\
(\% \text { by weight })\end{array}$} & \multicolumn{1}{|c|}{ Strength Parameters in MPa } \\
\cline { 2 - 5 } & & 7 days & 14 days & 28 days \\
\hline \multicolumn{5}{|c|}{ Compressive Strength of M30 Blended Concrete } \\
\hline M2 & $65 \%+25 \%+15 \%$ & 16.04 & 26.67 & 41.12 \\
\hline M6 & $(65 \%+20 \%+15 \%$ & 13.97 & 22.52 & 36.76 \\
\hline M10 & $65 \%+25 \%+10 \%$ & 14.64 & 23.78 & 34.86 \\
\hline M11 & $65 \%+20 \%+15 \%$ & 15.97 & 25.29 & 38.95 \\
\hline \multicolumn{5}{|c|}{ Split Tensile Strength of M30 Blended Concrete } \\
\hline M2 & $65 \%+25 \%+15 \%$ & 1.48 & 3.11 & 4.21 \\
\hline M7 & $(65 \%+20 \%+15 \%$ & 1.35 & 2.56 & 4.19 \\
\hline M8 & $65 \%+25 \%+10 \%$ & 1.47 & 2.49 & 3.94 \\
\hline M13 & $65 \%+20 \%+15 \%$ & 1.30 & 2.28 & 3.79 \\
\hline
\end{tabular}




\section{CONCLUSIONS}

Based on the experimental investigations and test results the following conclusions are documented as below-

1. The incorporation of polyethylene-glycol to concrete reduces water evaporation, which leads to an increase in water retention capacity of the concrete eventually leading to improved compressive strength. The adequacy of internalcuring by methods for PEG 400 applied to concrete is higher when $45 \mathrm{~kg} / \mathrm{m} 3$ water is included by procedures for $1 \mathrm{~kg} / \mathrm{m} 3$ of selfcuring concrete. The PEG 400 was more efficient than traditional curing concrete. The Performance of selfcuring agent is basically influenced by the concrete material and the w/c proportion.

2. For development of high strength concrete mixes (M30), use of micro silica is compulsory due to its inherent high reactive property and micro-filler capacity.

3. This improvement in strength is due to incessant cement hydration is because of retained water presence and also due to the conversion of calcium hydroxide into calcium silicate hydrate $(\mathrm{CSH})$ strengthening the interface aggregate-matrix transition zone which becomes less porous and more compact.

4. In development of high strength (M30) grade fly ash blended concrete mixes, both GGBS and Silica fume are required to be added to leverage the benefits of micro-filler capacity of micro silica and early strength attainment of metakaolin. Addition of silica fume (SF) to blended concrete mixes will enhance early hydration because of its high reactivity.

5. Optimally blended high strength grades M30 triple blended concrete mixes made of should be compacted $65 \% \mathrm{OPC}+25 \% \mathrm{FA}+10 \% \mathrm{GGBS}$ yields both required workability and desired compressive strengths. From this observation, it can be understood that GGBS in blended concrete mixtures imparts high strength. So, it is evident that both Fly Ash and GGBS are required in blended concrete mixes made with low water/powder ratio.

6. The early age strength of concrete with GGBS was lower than the control concrete. However, as the curing period is extended, the strength increases. The reason is that the pozzolanic reaction is slow and the formation of calcium hydroxide requires time.

7. The compressive strength properties of concrete increases as the Flyash and GGBScontent having $65 \%+25 \%+15 \%$ (M2,M3 and M4) having a higher compressive strength for mixes having $65 \%+20 \%+15 \%$ (M5,M6 andM7), $65 \%+25 \%+10 \%$ (M8,M9 and M10) increased up to an optimum point in $65 \%+20 \%+15 \%$ (M11, M12 and M13).
Hence it can be concluded that, there is an optimum level for the efficient use of GGBS content, which yields the highest strength in $65 \%+25 \%+15 \%$ (M2,M3 and M4). The optimum level of GGBS content for maximizing strengths is at about $30 \%$ of total binder content.

8. The split tensile strength properties of concrete increases as the Flyash and GGBScontent having and gradual increase in mix proportions of $65 \%+25 \%+15 \%(\mathrm{M} 2, \mathrm{M} 3$ and M4) having a higher compressive strength for mixes having a and slight decrease $\quad 65 \%+20 \%+15 \% \quad$ (M5,M6 andM7), $65 \%+25 \%+10 \%$ (M8, M9 and M10) increased up to an optimum point in $65 \%+20 \%+15 \%$ (M11, M12 and M13). Hence it can be concluded that, there is an optimum level for the efficient use of GGBS content, which yields the highest strength in $65 \%+25 \%+15 \%$ (M2,M3 and M4).

9. Addition of silica fume in concrete, beyond $25 \%$ does not improve the early strength. And it can be concluded that, after certain limit, the silica fume, which can produce hydration reaction, but behaves filler modules It indicates that, GGBS cannot be used efficiently as a binder, but rather as filler in the concrete.

\section{References}

1. Bentz D P and Stutzman P E (2006), "Curing, Hydration, and Microstructure of Cement Paste," ACI Materials Journal, 103 (5),pp.348-356.

2. Bilek B et al. (2002) "The possibility of self-curing concrete" Proceedings of Innovations and developments in concrete materialsand construction." International Conference University of Dundee,UK. 9-11 September 2002.

3. Dhir R K, Hewlett P C, Dyer T D, "Mechanisms of water retentionin cement pastes containing a selfcuring agent", Magazine ofConcrete Research, Vol. No 50, Issue No 1, 1998, pp. 85-90.

4. Mangaiarkarasi, V, Damodarasamy S R, "Selfcuring concrete today'sandtomorrow'sneedof construction world", INCRAC \& CT2005Proceedings International Conference on Recent Advances inConcrete and Construction Technology. Vol.2 pp.233-245, December 2005, Chennai.

5. Hans W Reinhardt and Silvia Weber (1998), "SelfCured HighPerformanceConcrete" Journal of Materials in Civil Engineering,November 1998, pp.101-109.

6. Nirav R Kholia, Bonita A Vyas, T G Tank (2013), " Effect OnConcrete By Different Curing Method and efficiency Of CuringCompounds," International Journal of Advanced EngineeringTechnology,Vol. IV, Issue II,April-June, 2013, pp.29-38. 
7. ACI Committee 308R-01, 2008, "Guide to Curing Concrete",American Concrete Institute, Farmington Hills, MI.

8. Wen-Chen Jau (2008) "Self-curing Concrete", United States PatentApplication Publication, Pub. No: U.S. 2008/0072799 A1, Publisheddate:Mar.27,2008.

9. A S El-Dieb (2007) "Self-curing Concrete: Water Retention, hydrationand moisture transport", Construction and Building Materials,Vol.21 (2007),pp. 1282-1287.

10. Tummala Suresh Kumar, Kosaraju Satyanarayana, Materials Today: Proceeding, 26 (2), 3228-3233, (2020).

11. V Srinivasa Reddy and R Nirmala, "Development of quaternary blended high-performance concretemade with high reactivity metakaolin", International Journal of Engineering \& Technology, Vol 7 (2.1), 2018,pp 79-83.

12. Satyanarayana, G.V.V., Saikiran, C.H, “ Effect on mechanical properties of M35 grade concrete by partial replacement of fine aggregate with copper slag”, IJITEE, 8 (12), pp 3759-3762.

13. Sateesh, N., Sampath Rao, P., Ravishanker, D.V., Satyanarayana, K., "Effect of Moisture on GFRP Composite Materials", Materials Today: Proceedings, 2 (4-5), pp. 2902-2908, (2015).

14. Reddy, V.M., Manikanta, S, "Mechanical properties of fibre reinforced self compacting concrete using rice husk ash", IJRTE, 8 (3), pp. 6412-6415, (2019). 